\title{
DEPÓSITO DE CAULIM DE TIJUCAS DO SUL (MINA FAZENDINHA, TIJUCAS DO SUL - PR)
}

\author{
JOÃO CARLOS BIONDI \& ELIZABETE DO ROCIO SANTOS
}

\begin{abstract}
THE TIJUCAS DO SUL KAOLIN DEPOSIT (FAZENDINHA MINE. TIJUCAS DO SUL-PR) The Tijucas do Sul sedimentary basin, about $45 \mathrm{Km}$ south of Curitiba (PR), is the largest deposit of kaolinitic clay from southern Brazil, containing estimated ore resources of $200 \mathrm{Mt}$. The basin developed on a gneissic and migmatitic basement and is being filled by sediments provided by the weathering and erosion of granites, volcano-sedimentary rocks and basalts. It contains quaternary agglomerates, sands, clays and clayish silts, deposited on fluvial flood plain and, subordinately, lacustrine environments. The intense lixiviation of superficial and shallow sediments by meteoric water acidified by organic matter rich sediments, is generating kaolinite and gibbsite, by feldspar desilicification, and gibbsite by kaolinite desilicification. The advanced aluminization of shallow and superficial sediments generated large quantity of gibbsite + kaolinite nodules. Chemical data suggests that this process occurred at least three other times, on periods when the paleo-surface of the sedimentary pile was exposed to weathering for long periods, which caused desilicification and kaolinization also of clay layers presentely buried. Black clays (AP facies) are the only with distinct chemical characteristics, outstanding by their high organic matter and $\mathrm{Y}$ contents and their ceramic properties, similar to ball clays. The $<0,04$ mm granulometric fraction of sediments contains 45 to $75 \%$ kaolinite, 2 to $41 \%$ quartz, I to $8 \%$ gibbsite and 1 to $10 \%$ titanium oxides (ilmenite + anatase + "other oxides"). Ti and Fe are incorporated by clay minerals, due to their high grade of crystalline structural disorder, or occur as micro-fragments of minerals brought in from basalt dikes. Kaolinite crystallinity is low to very low and crystals with b axis disordered are the most frequent. These structural characteristics related to the low degree of diagenesis and to the desilicification of kaolinites. MEV-EDS analysis indicated the absence of halloysite and the predominance of detritic, $<0.5 \mathrm{~mm}$, kaolinites over the "book-like" autigenic ones. Octahedrally shaped, high Ti micro crystals, probably anatase, occur mixed with clay minerals.
\end{abstract}

Keywords: Tijucas do Sul (PR-Brazil), kaolinite deposit, clay mineralogy and chemistry, genetic model.

Resumo A bacia sedimentar de Tijucas do Sul, situada cerca de $45 \mathrm{Km}$ ao sul de Curitiba (PR), é o maior depósito de argila caulinítica do sul do país, com recursos estimados em 200 Mt de minério. Situada em meio a gnaisses e migmatitos, recebe sedimentos originados pelo intemperismo e erosão de granitos, de rochas vulcano-sedimentares e diques de basalto. Está preenchida por aglomerados, areias, argilas e siltes argilosos quaternários, sedimentados em ambientes fluviais, de planície de inundação, e lacustres, em menor proporção. A intensa lixiviação, por águas superficiais acidificadas devido à presença de sedimentos ricos em matéria orgânica. está dessilicificando feldspatos dos sedimentos superficiais, gerando caulinita e gibbsita, e a caulinita, gerando gibbsita. Nos sedimentos mais próximos da superfície a aluminização avançada formou grande quantidade de nódulos de gibbsita + caulinita. Há indicações de que esse processo tenha ocorrido em ao menos três outros períodos, nos quais a paleo-superfície da pilha sedimentar ficou exposta à ação de águas meteóricas por longo tempo, proporcionando dessilicificação e caulinização também de camadas atualmente soterradas e distantes da superfície. A argila preta (fácies AP), lacustre, é a única com características químicas diferentes, destacando-se pelos seus teores elevados de matéria orgânica e de $\mathrm{Y}$ e por suas propriedades cerâmicaș, semelhantes às das ball clays. A fração dos sedimentos menor que $0,04 \mathrm{~mm}$ tem 45 a $75 \%$ de caulinita, 2 a $41 \%$ de quartzo, 1 a $8 \%$ de gibbsita e 1 a $10 \%$ de óxidos de titânio (ilmenita + anatásio + "outros óxidos"). O Ti e o Fe estão incorporados nos argilominerais, devido aos seus elevados graus de desordem estrutural, ou ocorrem como micro-fragmentos de minerais, trazidos dos diques de basalto. A cristalinidade das caulinitas é baixa a muito baixa, e predominam cristais com "desordem no eixo b". Estas características estruturais podem estar relacionadas ao baixo grau de diagênese dos sedimentos e à dessilicificação das caulinitas. Análises MEV-EDS mostraram que não há haloisita e que predominam caulinitas detríticas, menores que $0,5 \mathrm{~mm}$, sendo menos freqüentes as neoformadas, com estruturas "em acordeon". Ocorrem microcristais octaédricos, com teores altos de Ti, provavelmente de anatásio, misturados aos argilominerais.

Palavras-chave: Tijucas do Sul (PR), depósito de caulinita, química e mineralogia de argilas, modelo genético.

INTRODUÇÃO A bacia sedimentar de Tijucas do Sul situa-se no Estado do Paraná, a $45 \mathrm{Km}$ ao sul de Curitiba. Seus depósitos de argila caulinítica foram descobertos em 1980, pela equipe de prospecção da Mineração Tabatinga, até hoje detentora dos direitos de lavra. Foram bloqueadas reservas da ordem de $40 \mathrm{Mt}$ de minério na área da Mina Fazendinha (Fig. 1) e estima-se que os recursos contidos na bacia ultrapassem $200 \mathrm{Mt}$, o que faz de Tijucas do Sul o maior depósito de argila caulinítica do sul do país.

HISTÓRICO Oliveira (1927), Leonardos (1938), Ruellan (1945)e Maak (1953, 1961), apud Trein et al (1969), citaram a existência da bacia de Tijucas do Sul quando descreveram a fisiografia e mapearam o leste paranaense. Bigarella \& Salamuni (1959) e Bigarella et al (1961), quando descreveram os sedimentos da bacia de Curitiba, incluíram os de Tijucas, devido à semelhança e proximidade dos dois depósitos. Ab’Saber \& Bigarella (1961) discutiram a gênese das feições geomorfológicas da Serra do Mar no Estado do Paraná, abordando a configuração e gênese da bacia de Tijucas do Sul. Bigarella \& Salamuni (1962) estudaram a sedimentologia, composição e estruturas dos sedimentos das várzeas recentes do rio Iguaçu e afluentes na região de Curitiba, comparando-os aos de Tijucas, e discutem a possibilidade de ambos 
depósitos pertencerem a mesma bacia. Trein et al (1969) mapearam a região e, notando as diferenças estratigráficas e composicionais existentes entre as bacias de Curitiba e Tijucas, propuzeram serem bacias independentes. Aumond (1993) realizou trabalhos de geologia e de caracterização tecnológica do material argiloso da região de Tijucas do Sul, revelando a existência dos depósitos de argila caulinítica.

GEOLOGIA REGIONAL A bacia de Tijucas do Sul tem forma ovalada, com cerca de $12,5 \mathrm{Km}$ no seu eixo maior e 9,1 $\mathrm{Km}$ no menor (Fig. 1). Localiza-se na porção sul da chamada "Superfície de Curitiba" (Ab’Saber \& Bigarella 1961), com altitude média de $450 \mathrm{~m}$. limitada por granitos e pelas rochas vulcano-sedimentares da Formação Guaratubinha cujas áreas de ocorrências têm altitudes entre 850 e 1150 metros. Contém sedimentos aluviais quaternários depositados pelos rios que formam o rio da Várzea, afluente do rio Negro, que separa os Estados do Paraná e Santa Catarina na região. A bacia de Tijucas do Sul é um baixo estrutural formado dentro dos gnaisses e migmatitos transamazônicos do Complexo Costeiro(DNPM-MINEROPAR 1989). Foi e está sendo preenchida por sedimentos originados pela erosão de rochas do Complexo Costeiro, da Formação Guaratubinha, situada a NE, dos granitos hrasilianos Morro Redondo e Agudos, situados, respectivamente, a leste e a oeste da bacia, e de inúmeros diques de basalto juro-cretácicos (Fig. 1).

Foram feitos três furos estratigráficos nas regiões de Contenda, Fazendinha e AD-44 (Fig. 1), que revelaram a presença de camadas de sedimentos clásticos com espessuras totais de 7,50, 15,60 e 6,90 me niveis argilosos com 4,80,8,30 e 0,40 m, respectivamente. $\mathrm{Na}$ base da coluna de sedimentos há areias (Contenda e AD-44) ou aglomerados com matriz argilosa (Fazendinha), que estão cobertos por camadas de argila e argilas sílticas, com muitas lentes de areias e aglomerados oligomíticos de origem fluvial, com seixos arredondados de quartzo, quartzitos, granitos e migmatitos. As camadas de argila têm cores creme, cinza clara ou preta (rara). São cobertas por solos argilosos e turfosos pretos e solos argilosos marrons. Em quase toda a bacia, os solos e as camadas superiores de argila têm nódulos brancos de gibbsita e caulinita, com formas irregulares e distribuição variada, cujas dimensões atingem até 10 $\mathrm{cm}$. Em alguns locais há uma "linha de pedras" (stone line) entre os solos preto e marrom (Santos 2000).

GEOLOGIA DA ÁREA DA MINA FAZENDINHA Não há afloramentos naturais em toda a região central da bacia de Tijucas, o que faz com que o mapa geológico (Fig. 2) se restrinja a área da cava da mina. Nesta área, o intemperismo apagou ou modificou quase todas as feições primárias dos sedimentos, o que levou a mapear fácies de intemperismo, separadas conforme as características texturais e composicionais impostas sobre as camadas de sedimentos.

O substrato de todo o pacote sedimentar que ocorre na área da mina é uma camada de silte maciço, com cores alaranjada ou amarelo-ocre, com muitas lentes de aglomerados polimíticos composto por seixos arredondados de quartzo, gnaisse e migmatito em matriz areno-síltica. Este silte foi identificado como fácies AS e sobre ele, sucessivamente, estão as fácies AP, argila preta, SC, silte argiloso, AC, argila síltica e AG, argila síltica gibbsítica, todas de minério. O depósito é capeado pelas fácies SM, solo marrom, e $\mathrm{SP}$, solo preto superficial. A fácies $\mathrm{AA}$, composta por aglomerados e areias, ocorre na base da pilha ou intercalada em AC. SM, SP

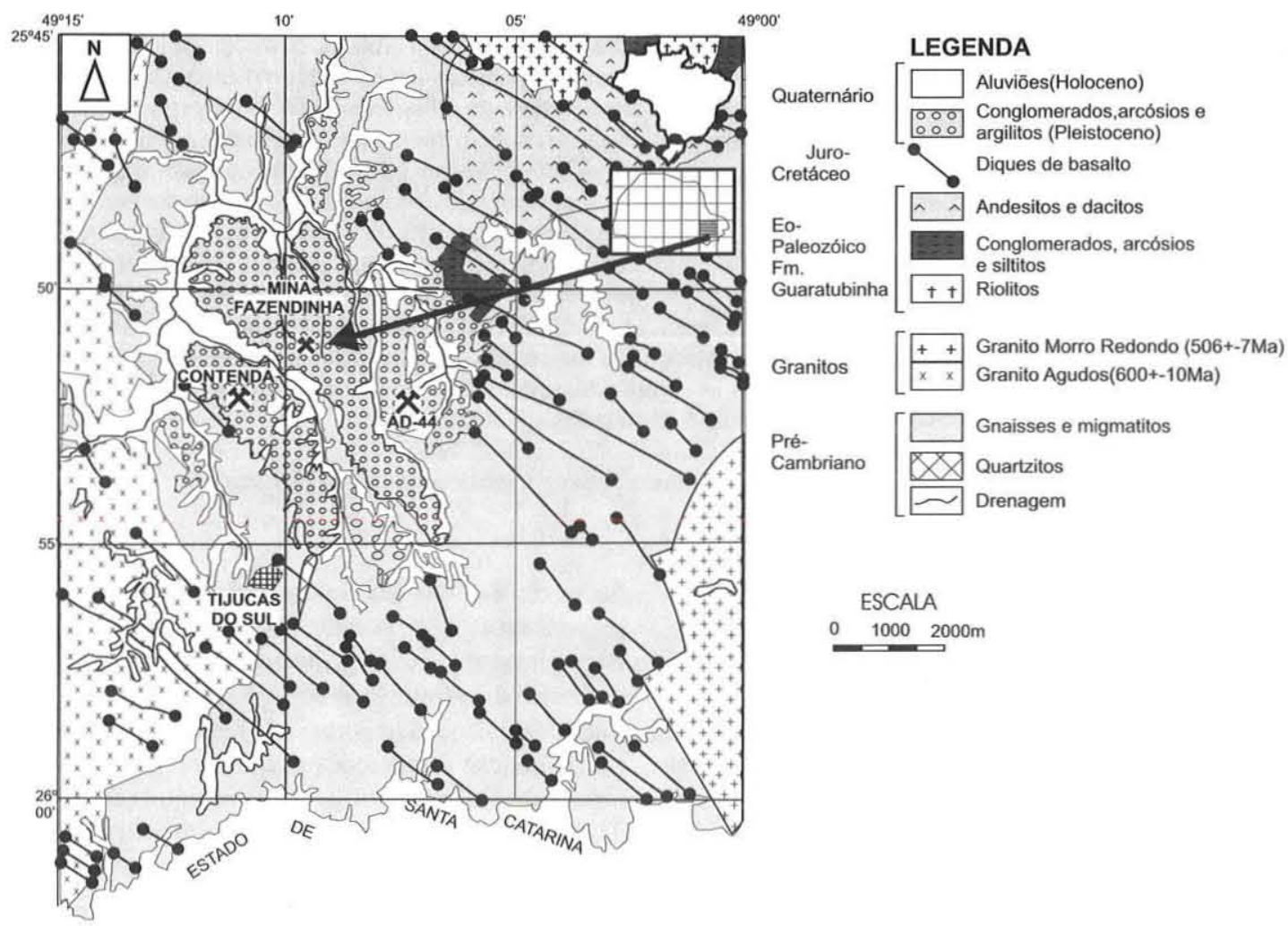

Figura I-Geologia da região da bacia sedimentar quaternária de Tijucas do Sul (PR). Para que se destacassem no mapa, a espessura dos diques de basalto está exagerada, mas a quantidade está muito aquém da realidade. 
e AA não são minérios (Figs 2 e 3 ).

$\mathrm{Na}$ parte leste da cava, sobre o substrato, há lentes de argila preta, plástica e muito carbonosa, identificadas como fácies AP (Figs 2 e 3). Esta argila é o minério de melhor qualidade produzido na mina, devido a ter características de "ball-clav" - argilas de alta plasticidade e muito refratárias que ficam muito brancas após queimadas a mais de $1000^{\circ} \mathrm{C}$, essenciais nas fórmulas de muitos produtos cerâmicos. No centro e na parte oeste da mina a fácies AP não ocorre, e a primeira camada acima do substrato é de silte argiloso cor creme acinzentada, identificado como fácies SC. É o nível argiloso mais importante da mina, devido a sua espessura, continuidade lateral e suas características cerâmicas, favoráveis ao uso na indústria de cerâmica branca. Essa fácies é lavrada como minério, denominado "Mina I ou II", conforme suas propriedades cerâmicas. As argilas SC estão cobertas por argilas sílticas maciças, cor cinza, da lácies $\mathrm{AC}$, um minério silicoso refratário, que tem lentes de areia com espessuras decimétricas (Figs 2, 3 e 4B). Essa fácies é recoberta pelo minério denominado "argila Susi", correspondente à fácies $\mathrm{AG}$, constituída por argilas sílticas cinzaesbranquiçadas, caracterizadas por conterem muitos nódulos de gibbsita+caulinita, (Figs 2, 3 e 4A, B e C). Os nódulos têm dimensões de até $10 \mathrm{~cm}$, são brancos, duros, com formas variadas, esferoidais, botrioidais e tubulares (Figs 4C e D). É comum que vários nódulos coaleçam. formando aglomerados decimétricos de cor hranca-leite. O núcleo dos nódulos é maciço, duro, microcristalino, cor creme amarronzada, composto por gibbsita (predominante) e caulinita. Têm um envoltório com espessura submilimétrica, pulverulento, cor branca-leite, composto por uma mistura de gibbsita, caulinita e quartzo microcristalinos. A "argila
Susi" é minério usado pela indústria de refratários. É a camada de minério mais próxima da superfície.

Cobrindo todas as fácies mencionadas, há um manto de solo cor ocre ou marrom, identificado como fácies SM, recoberto por outro manto de solo, orgânico, preto, síltico-argiloso, superficial, denominado fácies SP(Figs. 2,3e 4A). Os nódulos de gibbsita+caulinita estão presentes em igual quantidade nas fácies AG, SM e SP.

Apesar das modificações causadas pelo intemperismo, é possível reconhecer que as fácies $\mathrm{SC}, \mathrm{AC}$ e $\mathrm{AG}$ são de sedimentos fluviais de planície de inundação, a APé lacustre e a AA é de canal fluvial (Santos 2000).

CARACTERÍSTICAS DAS FÁCIES MAPEADAS Granulometria A granulometria de amostras das fácies que compõem as seções A, B e C (Figs. 2 e 3) foi analisada pelo método de peneiramento (fração maior que $62 \mu \mathrm{m}$ ) e pipetagem (fração menor). Os resultados estão sintetizados na Tabela 1.

Considerando a composição média das amostras, exceto os aglomerados AA, em todas as outras fácies predomina a fração argila, que perfaz entre 60 e $77 \%$ em peso dos sedimentos. A fração areia + nódulos de gibbsita + seixos é a segunda mais comum, com 12 a $24 \%$ ( $53 \%$ nos aglomerados), e a fração silte é a menos comum ( 9 a 24\%). Embora a presença dos nódulos de gibbsita altere a distribuição granulométrica original, sobretudo da fração grosseira, é notável, nas três seções, a ocorrência de inversões no sentido de crescimento dos grãos. Estas inversões ocorrem nas posições nas quais foram coletadas as amostras TA-8, na seção TA, TB-4 ou 4.1, na seção TB, e TC-8, 11 e 13 na seção TC (Tabela I e Fig. 3). Vê-se, na figura 2, que a amostra TC-11 é de aglomerado, e os

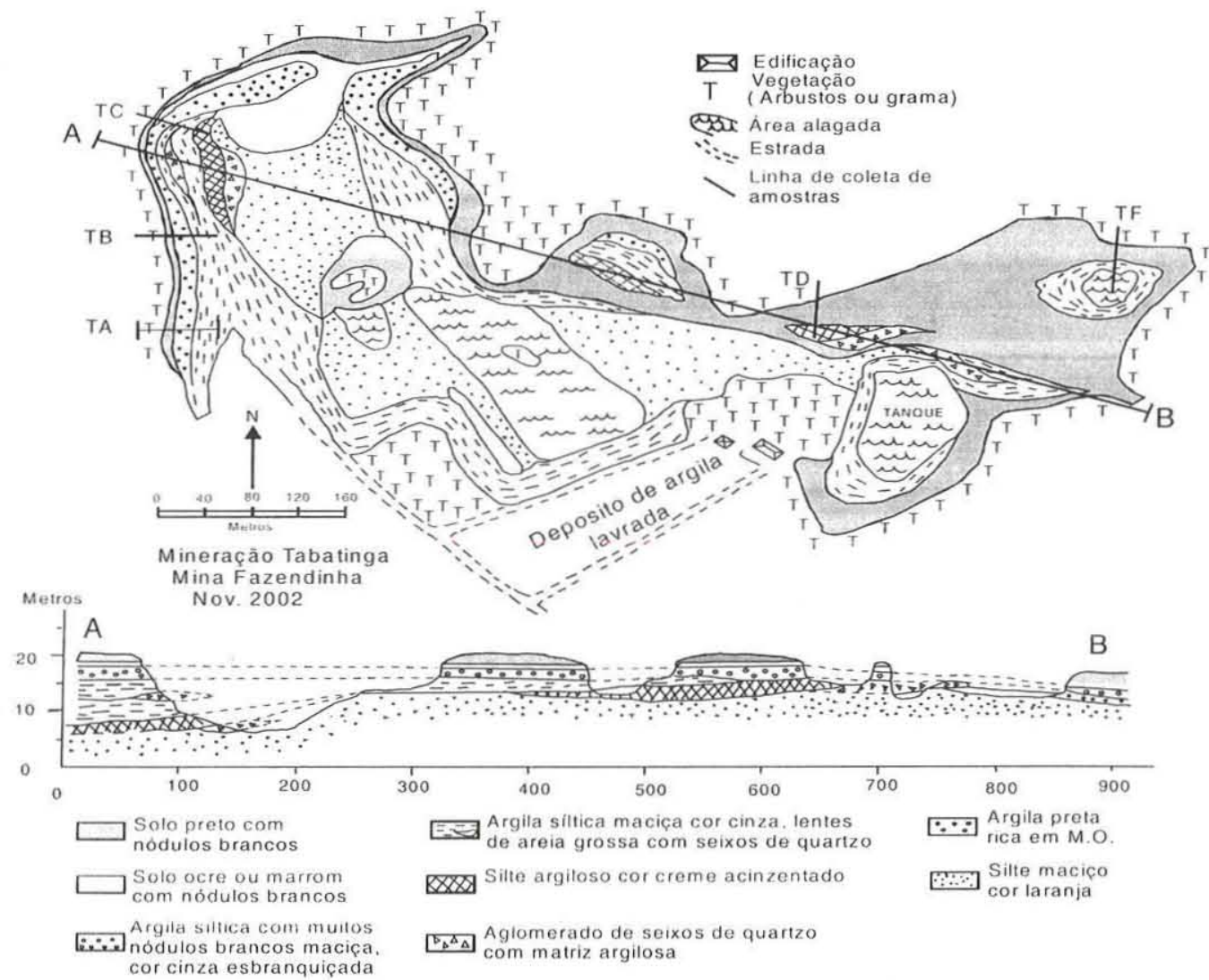

Figura 2 - Mapa e seção geológicos da cava da mina Fazendinha, na bacia de Tijucas do Su (PR). 


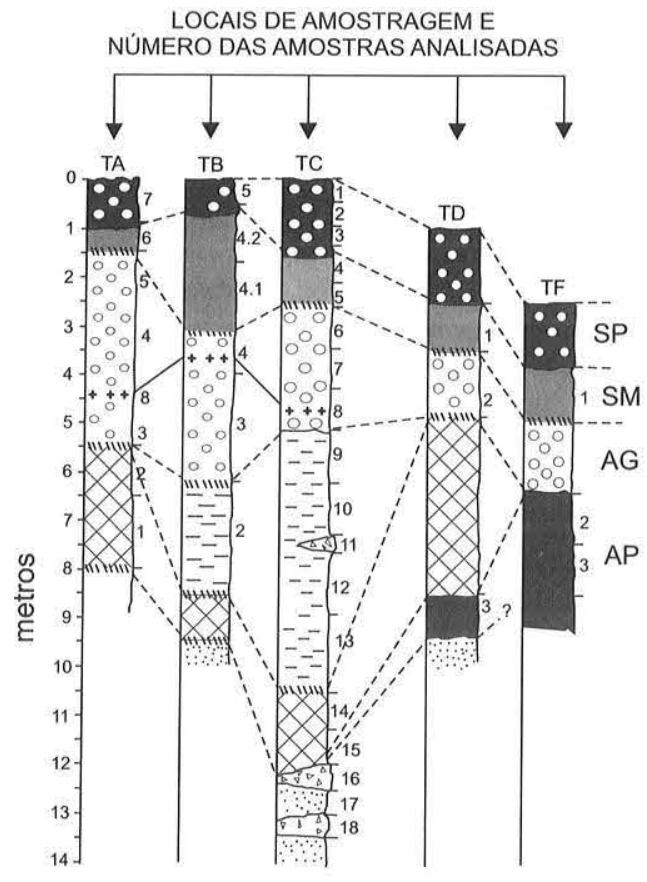

\begin{abstract}
FÁCIES
SP ${ }^{\circ}$ solo preto, siltico-argiloso com muitos fragmentos vegetais

SM $\square$ solo ocre ou marrom, com nódulos de gibbsita

AG ${ }^{\circ}{ }_{0}{ }^{\circ}$ argila síltica cinza-esbranquiçada com muitos nódulos de gibbsita $\mathrm{AC}=$ argila síltica maciça, cinza, com lentes de areia

SC $X X$ silte argiloso creme-acinzentado

AA $\sqrt{\Delta_{\triangle}^{\nabla} \Delta \nabla}$ aglomerado de seixos de quartzo com matriz de areia

AP argila preta, muito carbonosa

SA $: i::$ silte maciço alaranjado +++ posições estratigráficas onde há aumento da granulometria
dos sedimentos
\end{abstract}

Figura 3 - Composição sedimentar e correlação lateral das diversas fácies de sedimentos, minérios argilosos e solos da mina Fazendinha. As posições dessas seções estão indicadas na figura 2.

grãos das frações silte c areiatnódulos+scixos dos sedimentos diminuem desse horizonte para baixo, até a posição da amostra TC-13, a partir da qual volta a crescer, até uma outra lente de aglomerado, na base da pilha sedimentar (amostra TC-16). Este tipo de variação granulométrica sugere que, da base da pilha sedimentar (amostra TC-16) para cima, houve diminuição da energia do ambiente de sedimentação até a posição da amostra TC-13, aumento até TC-11, nova diminuição até TC-8, seguido de novo aumento até a TC-5. O mesmo tipo de interpretação vale para as seções TA e TB. Notar, na figura 2 e Tabela 1, que os pontos de inversĩo que ocorrem nas posições das amostras TA-8 - TB-4 TC-8 e TB-2 - TC-11 estão praticamente nivelados, com diferenças de altitude de no máximo um metro. Isto sugere que as inversões tenham ocorrido em toda a região da mina em ao menos três momentos da sedimentação, correspondentes, na seção TC, às posições das amostras TC-8, TC-11 e TC 13.

Uma explicação para estas variações granulométricas dos sedimentos seria o deslocamento lateral do leito do rio ao qual a sedi- mentação está geneticamente relacionada. O esquema mostrado na figura 5 ilustra este processo. Nos momentos de sedimentação (épocas de inundações) denominados "tempo 1, 2 e 3" (Figs. 5A, B e C), até o "tempo N+M" (Fig. 5D), conforme a bacia subside e é preenchida por sedimentos, o rio migra lateralmente. Este processo faz com que o tamanho dos grãos dos sedimentos varie verticalmente em cada ponto da bacia, e reproduz as variações granulométricas observadas nas seções TA, TB e TC (Fig. 5D). A fácies lacustre AP, das seções TD e TF (Figs. 2 e 3), deve ter sido formada em um lago perene, que existiu em uma dada época da sedimentação e foi posteriormente soterrado (Figs. 5C e D).

Composição química dos sedimentos e a neoformação de caulinita CARACTERÍSTICAS QUIMICAS DOS SEDIMENTOS A tabela 2 mostra as médias das análises químicas da fração menor que $(0,04$ $\mathrm{mm}$ ( $<325$ mesh) de 34 amostras de canal coletadas em cinco seções geológicas feitas na cava da Mina Fazendinha. A figura 2 localiza as seções geológicas e a figura 3 mostra as posições de

Tabela 1 - Granulometria de solos, minério e sedimentos das fácies das seções $A, B$ e C. As amostras estão organizadas conforme suas posições estratigráficas (vide figuras 2 e 3).

\begin{tabular}{|c|c|c|c|c|c|c|}
\hline \multirow[b]{2}{*}{ Amostra } & \multirow[b]{2}{*}{ Facies } & \multicolumn{5}{|c|}{ \% dopesolotal } \\
\hline & & $\begin{array}{c}\text { Fraçẫo } \\
\text { argila }\end{array}$ & $\begin{array}{l}\text { Fracciale } \\
\text { silte }\end{array}$ & $\begin{array}{l}\text { Fraçiòo areia } \\
\text { + nódulos } \\
\text { de gihbsilat } \\
\text { seixos }\end{array}$ & \multicolumn{2}{|c|}{$\begin{array}{c}\text { Variaçào da } \\
\text { granulometria } \\
\text { (as setas indicam o } \\
\text { sentido em que } \\
\text { aumenta a } \\
\text { granulometria das } \\
\text { amostras) }\end{array}$} \\
\hline \multirow{6}{*}{ MÉDIAS } & $S P$ & 60 & is & 22 & \multirow{6}{*}{ Silte } & \multirow{6}{*}{$\begin{array}{l}\text { Areia }+ \\
\text { nódulos de } \\
\text { gibbsila }+ \\
\text { seixos }\end{array}$} \\
\hline & SM & 70 & 9 & 21 & & \\
\hline & $\mathrm{AG}$ & 77 & 11 & 12 & & \\
\hline & $\mathrm{AC}$ & 61 & 15 & 24 & & \\
\hline & $\mathrm{SC}$ & 71 & 11 & 18 & & \\
\hline & AA & 23 & 24 & 53 & & \\
\hline \multicolumn{7}{|c|}{ Resultados das análises granulométricas das amostras } \\
\hline \multicolumn{7}{|c|}{ SECÃO TA } \\
\hline TA-7 & SP & 73 & 13 & 14 & \multirow{8}{*}{ 4 } & \multirow{8}{*}{4} \\
\hline TA - 6 & SM & 75 & 7 & 18 & & \\
\hline TA $\cdot 5$ & $\mathrm{AG}$ & 66 & 7 & 18 & & \\
\hline TA 4 & $\mathrm{AG}$ & 89 & 5 & 6 & & \\
\hline TA -8 & $\mathrm{AG}$ & 74 & 24 & 2 & & \\
\hline$T A-3$ & $\mathrm{AC}$ & 79 & 10 & 11 & & \\
\hline $111: 2$ & Se & 81 & 5 & 14 & & \\
\hline $\mathrm{AA} \cdot 1$ & $\mathrm{SC}$ & 78 & 3 & 19 & & \\
\hline \multicolumn{7}{|c|}{ SECAOO TB } \\
\hline TB-5 & $S P$ & 47 & 23 & 30 & \multirow[t]{6}{*}{4} & \\
\hline TB.4.2 & $S M$ & 66 & 8 & 26 & & \\
\hline T B-4.I & SM & $\$ 6$ & 3 & 11 & & \\
\hline $\mathrm{TB}-4$ & $A G$ & 90 & 5 & 5 & & \\
\hline TB.3 & $\mathrm{AG}$ & 80 & 13 & 7 & & \\
\hline TB-2 & $A C$ & 6.5 & 14 & 21 & & \\
\hline \multicolumn{7}{|c|}{ SEÇÃOTC } \\
\hline$T C-5$ & SM & 53 & 17 & 30) & \multirow[t]{12}{*}{4} & \multirow[b]{12}{*}{$\nabla$} \\
\hline TC. 6 & $\mathrm{AG}$ & 61 & 11 & 28 & & \\
\hline TC.? & $\mathrm{AC}$ & 76 & 11 & 13 & & \\
\hline TC. 8 & $\mathrm{AG}$ & 79 & 10) & 11 & & \\
\hline TC. -9 & $A C$ & 74 & 14 & 12 & & \\
\hline TC. 10 & $A C$ & 51 & 21 & 28 & & \\
\hline TC. II & $\mathrm{AA}$ & 24 & 23 & 53 & & \\
\hline $\mathrm{TC}-12$ & $A C$ & 46 & 17 & 37 & & \\
\hline $\mathrm{TC} \cdot 13$ & $A C$ & 68 & 8 & 24 & & \\
\hline TC. 14 & SC & 75 & 13 & 12 & & \\
\hline TC. 15 & $\mathrm{SC}$ & 49 & 24 & 27 & & \\
\hline TC.16 & $A A$ & 22 & 26 & 52 & & \\
\hline
\end{tabular}



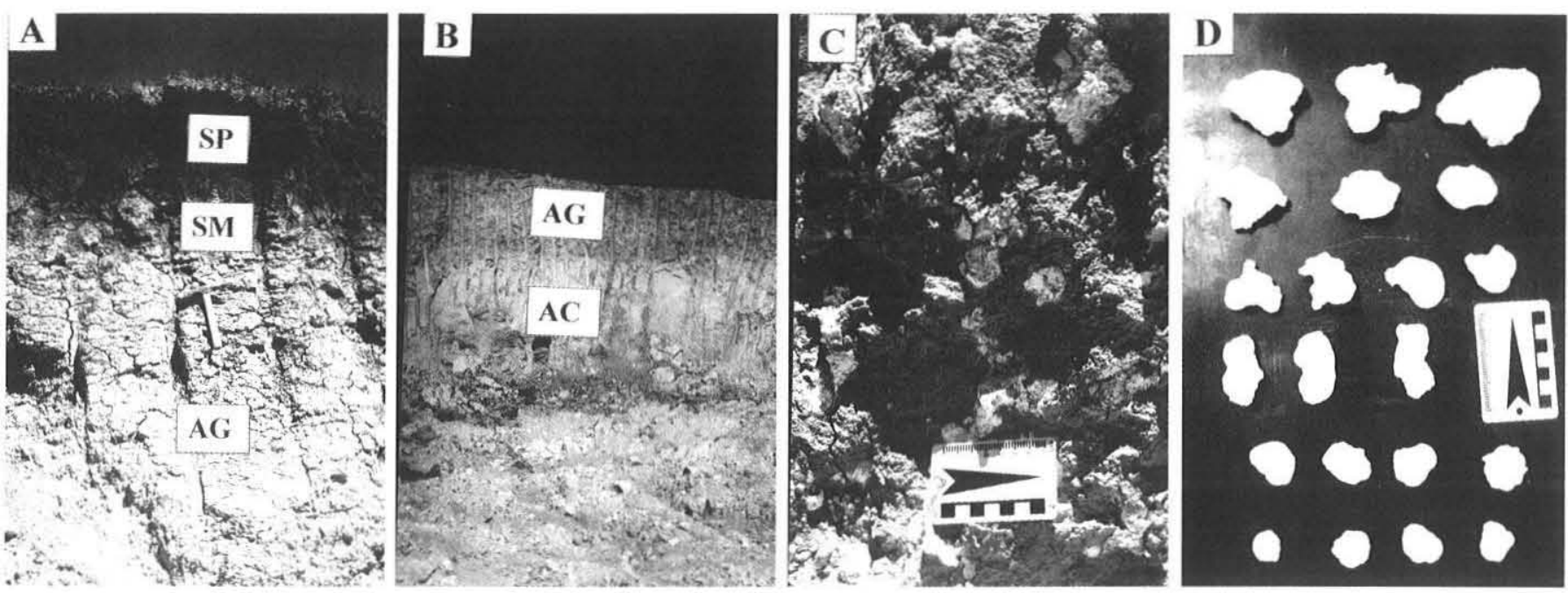

Figura 4-(A) Fácies SP (solo preto), superficial, e SM (solo marrom), que recobrem a "argila Susi" (fácies AG). (B) Frente de lavra já decapeada. A camada superior é a fácies AG e a inferior é a AC. (C) Nódulos brancos de gibbsita + caulinita dentro da fácies $A G$. (D) Conjunto de nódulos retirados da fácies $A G$, com várias formas e dimensões.
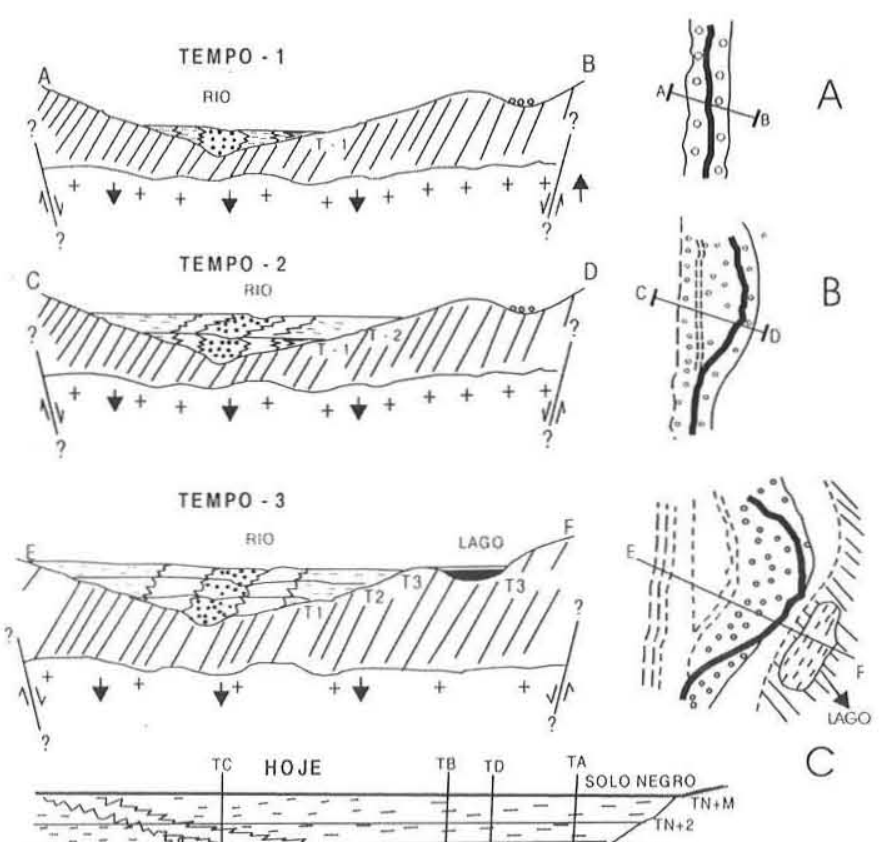

C



Figura 5 - Esquema que explica as variações granulométricas observadas nos sedimentos das seções TA, TB e TC. Os resultados são os mesmos se o rio migrar primeiro para o lado direito e depois para o esquerdo ou vice-versa. coleta de amostras em cada seção. As amostras foram fundidas com tetraborato de lítio, moldadas em pastilhas de vidro e foram analisadas por fluorescência de raios $\mathrm{X}$, com um equipamento Philips PW-2400 do LAMIR - Laboratório de Análises de Minerais e Rochas, da Universidade Federal do Paraná. A perda ao fogo foi determinada em aparelho de Análise Termo Gravimétrica, marca LECO modelo 601, também do LAMIR.

Comparadas às argilas de outros depósitos, todas as amostras analisadas têm teores muito elevados em $\mathrm{TiO}_{2}$ e Fe $\mathrm{F}_{2}$ (Tabela 2) e baixos em $\mathrm{K}_{2} \mathrm{O}$ e $\mathrm{Na}_{2} \mathrm{O}$. Os teores elevados em titânio e ferro provavelmente são consequiência da presença de muitos diques de basalto em torno da bacia de Tijucas do Sul (Fig. 1). O intemperismo e a erosão desses diques liberou grandes quantidades de ilmenita, magnetita e rutilo que foram integrados aos sedimentos da bacia. Devido à presença de rochas feldspáticas nas áreas fonte de sedimentos para a bacia de Tijucas, esses sedimentos deveriam ter teores mais elevados em $\mathrm{Na}$ e K. Os baixos teores devem ser consequiência de dois fatores: (a) foram analisadas (Tabela 2) as frações $<0,04 \mathrm{~mm}$ das amostras, e é sabido que a quantidade de feldspatos diminui na mesma proporção que diminui o tamanho dos grãos da fração analisada e, (b) como será discutido adiante, os feldspatos trazidos até a bacia foram e estão sendo destruídos pela caulinização e gibbsitização dos sedimentos.

Os teores médios em elemento maiores das amostras das várias fácies são parecidos (Fig. 6A-F), e as fácies são melhor separadas em diagramas binários (Fig. 7A-C) que nos ternários. Os diagramas ternários diferenciam apenas as argilas pretas $\mathrm{AP}$ pelos maiores teores em $\mathrm{Na}_{2} \mathrm{O}$ e $\mathrm{K}_{2} \mathrm{O}$ em relação ao $\mathrm{TiO}_{2}$ (Fig. 6F) e os siltes argilosos $\mathrm{SC}$ pelos teores elevados em $\mathrm{Fe}, \mathrm{O}_{3}$ em relação ao $\mathrm{SiO}$, e

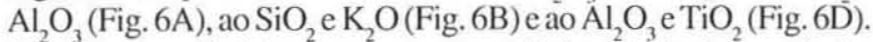
Os diagramas binários mostram que as fácies AA (aglomerados) e SM (solo marron) são mais silicosas que as outras (Figs 7A-C), e as fácies $\mathrm{SP}$ e AC têm teores de $\mathrm{Fe}_{2} \mathrm{O}_{3}$ maiores (Fig. 7B). Os elementos maiores, portanto, servem apenas para diferenciar as fácies AP e SC das outras.

A fácies argila preta (AP) tem proporções de $\mathrm{Y}$ em relação a $\mathrm{Zr}$ e $\mathrm{Sr}$ (Fig. 6G) e de Y em relação a Zre Nb (Fig. 7H) muito diferentes 
de todas as outras. Esta diferença é ressaltada nos diagramas binários Y vs. Zr (Fig. 7D), Y vs. Sr (Fig. 7E)e Y vs. Rb (Fig. 7F). O diagrama Rb vs Nbé o que melhor diferencia todas as fácies. Notase que: (a) a fácies APé formada em ambiente muito diferente das outras, confirmando o anteriormente discutido (Fig. 5); (b) as fácies AC, AG, AG e SM têm composições químicas muito parecidas, o que sugere que tenham sido geradas em condições semelhantes; (c) a fácies $\mathrm{SC}$ tem pouco mais $\mathrm{Fe}_{2} \mathrm{O}_{3}$ que as outras; (d) que os teores em $\mathrm{SiO}_{2}$ das fácies são muito variáveis; (e) que todas as fácies têm teores elevados em $\mathrm{Fe}_{2} \mathrm{O}_{3}$ e $\mathrm{TiO}_{2} \mathrm{e}$; (f) que o melhor diagrama para diferenciar as fácies quimicamente é o Rb vs. Nb. NEOFORMAÇÃO DE CAULINITA A figura 8 mostra como variam os teores de $\mathrm{SiO}_{2}, \mathrm{Al}_{2} \mathrm{O}_{3}, \mathrm{TiO}_{2}, \mathrm{Rb}, \mathrm{Y}, \mathrm{Nb}$ e $\mathrm{Zr}$ ao longo das seções TC e TA. Em ambas seções nota-se que: (a) o teor de sílica varia de modo inversamente proporcional ao de alumina, (b) a variação dos teores desses óxidos é gradual, com o teor de $\mathrm{SiO}_{2}$ diminuindo e o de $\mathrm{Al}_{2} \mathrm{O}_{3}$ aumentando de cima para baixo, em quatro ciclos na seção TC e ao menos um na TA (Fig. 8 e Tabela 2) e, (c)

Tabela 2 - Teores médios das frações granulométricas $<0,04 \mathrm{~mm}$ de amostras das fácies de solos, minérios e sedimentos da mina Fazendinha (Tijucas do Sul-PR). s = desvio padrão.

\begin{tabular}{|c|c|c|c|c|c|c|c|c|c|c|c|c|c|c|c|c|c|c|}
\hline $\begin{array}{c}\text { Fácies } \\
\left(\mathrm{n}^{\circ} \text { amostras) }\right.\end{array}$ & & $\mathrm{SiO}_{2}$ & $\mathrm{Al}_{2} \mathrm{O}_{3}$ & $\mathrm{TiO}_{2}$ & $\mathrm{Fe}_{2} \mathrm{O}_{3}$ & $\mathrm{MnO}$ & $\mathrm{MgO}$ & $\mathrm{CaO}$ & $\mathrm{Na}_{2} \mathrm{O}$ & $\mathrm{K}_{2} \mathrm{O}$ & $\mathrm{P}_{2} \mathrm{O}_{5}$ & P.F. & Total & $\mathrm{Rb}$ & $\mathrm{Sr}$ & $\mathrm{Y}$ & $\mathrm{Zr}$ & $\mathrm{Nb}$ \\
\hline \multirow[t]{2}{*}{ SP (3) } & média & 53.80 & 28.59 & 2.94 & 3.37 & 0.01 & 0.27 & 0.13 & 0.09 & 0.18 & 0.09 & 10.21 & 99.69 & 12 & 28 & 31 & 970 & 39) \\
\hline & s & 1.25 & 0.65 & 0.36 & 0.45 & $<0.01$ & 0.06 & 0.05 & 0.04 & 0.05 & 0.06 & 0.37 & 0.24 & 10 & 5 & 7 & 117 & 6 \\
\hline \multirow[t]{2}{*}{ SM (4) } & média & 61.06 & 21.86 & 2.20 & 1.65 & 0.01 & 0.17 & 0.10 & 0.06 & 0.18 & 0.03 & 12.46 & 99.79 & 11 & 13 & 21 & 945 & 31 \\
\hline & 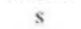 & 12.45 & 7.73 & 0.51 & 0.82 & $<0.01$ & 0.04 & $<0.01$ & 0.02 & 0.07 & 0.00 & 4.17 & 0.13 & 4 & 2 & 2 & 104 & 6 \\
\hline \multirow[t]{2}{*}{ AG (9) } & média & 52.54 & 26.83 & 2.25 & 0.86 & $<0.01$ & 0.05 & 0.11 & 0.08 & 0.17 & 0.03 & 16.83 & 99.73 & 11 & 14 & 30 & 539 & 24 \\
\hline & s & 4.82 & 2.78 & 0.19 & 0.17 & $<0.01$ & 0.06 & 0.03 & 0.05 & 0.05 & 0.01 & 1.79 & 0.22 & 4 & 9 & 22 & 436 & 19 \\
\hline \multirow[t]{2}{*}{$\mathrm{AC}(5)$} & média & 56.04 & 27.69 & 2.22 & 2.11 & 0.01 & 0.02 & 0.10 & 0.04 & 0.22 & 0.03 & 11.37 & 99.85 & 7 & 21 & 21 & 1193 & 34 \\
\hline & $\therefore$ & 4.77 & 4.01 & 0.34 & 1.39 & 0.01 & 0.02 & 0.01 & 0.02 & 0.09 & 0.01 & 3.97 & 0.19 & 1 & 6 & 2 & 271 & 4 \\
\hline \multirow[t]{2}{*}{$\mathrm{SC}(5)$} & média & 48.17 & 28.43 & 2.18 & 6.89 & 0.01 & 0.05 & 0.11 & 0.08 & 0.21 & 0.04 & 13.46 & 99.62 & 13 & 22 & 29 & 1020 & 37 \\
\hline & & 2.60 & 3.63 & 0.11 & 8.93 & $<0.01$ & 0.02 & 0.03 & 0.05 & 0.06 & 0.01 & 8.08 & 0.08 & 2 & 13 & 3 & 138 & 2 \\
\hline \multirow[t]{2}{*}{$\mathrm{AA}(3)$} & média & 63.10 & 18.87 & 1.54 & 1.30 & 0.02 & 0.09 & 0.09 & 0.07 & 0.18 & 0.04 & 14.53 & 99.84 & 9 & 17 & 16 & 1063 & 24 \\
\hline & 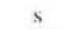 & 2.92 & 3.50 & 0.19 & 0.48 & 0.01 & 0.08 & 0.01 & 0.06 & 0.11 & 0.01 & 3.14 & 0.22 & 2 & 3 & 9 & 287 & 4 \\
\hline \multirow[t]{2}{*}{ AP (8) } & média & 56.49 & 27.63 & 1.59 & 0.99 & 0.01 & 0.14 & 0.14 & 0.15 & 0.23 & 0.02 & 12.44 & 99.83 & 15 & 30 & 109 & 351 & 28 \\
\hline & 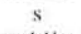 & 1.54 & 2.90 & 0.20 & 0.16 & $<0.01$ & 0.06 & 0.06 & 0.01 & 0.02 & 0.01 & 1.30 & 0.26 & 5 & 10 & 65 & 61 & 3 \\
\hline SA (1) & média & 55.11 & 30.82 & 2.58 & 1.10 & $<0.01$ & 0.03 & 0.10 & 0.05 & 0.20 & 0.02 & 10.33 & 100.34 & 16 & 15 & 26 & 601 & 43 \\
\hline
\end{tabular}
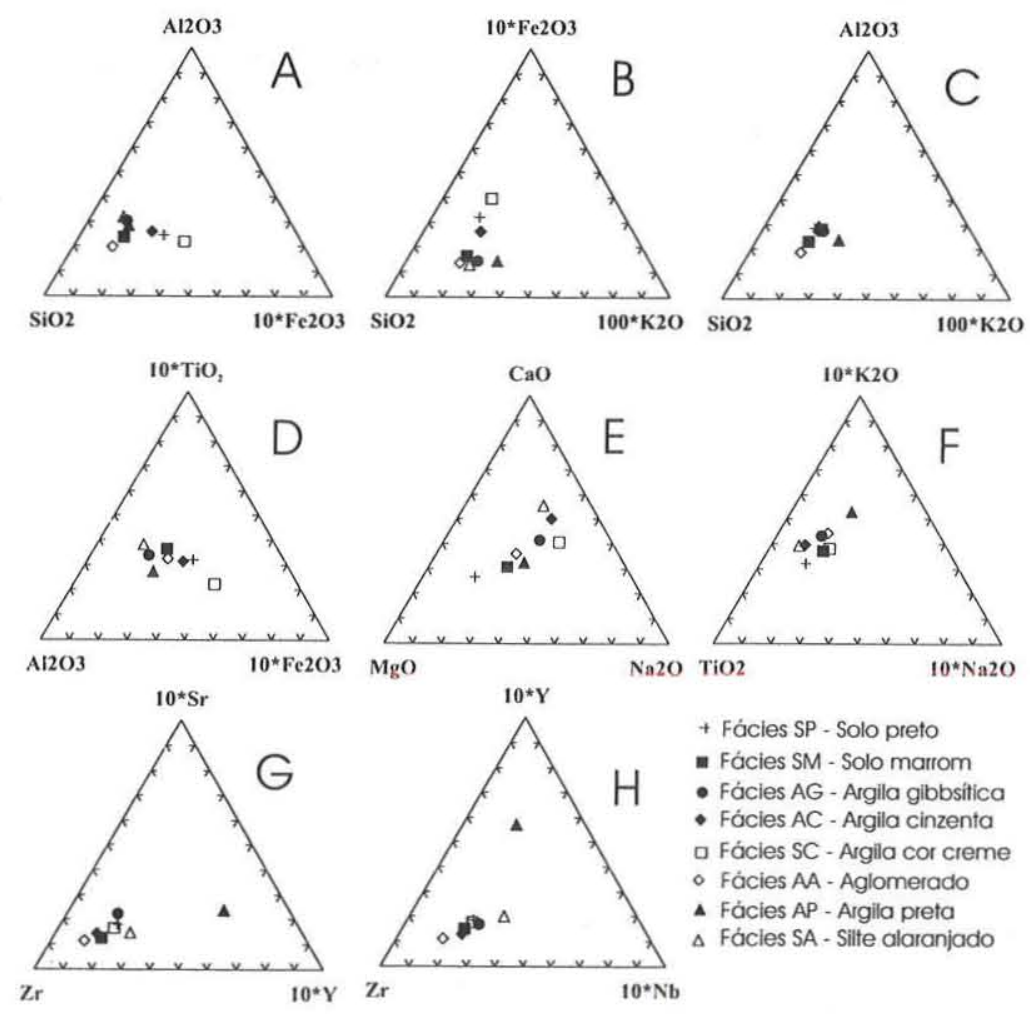

+ Fácies SP - Solo preto

- Fácies SM - Solo marrom

- Fácies AG - Argila gibbsítica

- Fácies AC - Argila cinzenta

口 Fácles SC - Argila cor creme

- Fácies AA - Aglomerado

$\Delta$ Fácies AP - Argila preta

$\triangle$ Fácles SA - Silte alaranjado

Figura 6-Diagramas ternários: (A) $\mathrm{SiO}_{2}$ vs. $\mathrm{Al}_{2} \mathrm{O}_{3}$ vs. $10 x \mathrm{Fe}_{2} \mathrm{O}_{3}$ (B) $\mathrm{SiO}_{2}$ vs. $10 x \mathrm{Fe}_{2} \mathrm{O}_{3}$ vs. $100 x \mathrm{~K}_{2} \mathrm{O}_{1}$ ( $\mathrm{C}_{\text {) }} \mathrm{SiO}_{2}$ vs. $\mathrm{Al}_{2} \mathrm{O}_{3}$ vs. $100 x \mathrm{~K}_{2} \mathrm{O}_{\text {, }}$

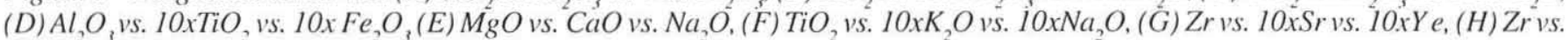
$10 x Y$ vs. $10 x \mathrm{Nb}$. Entre todas as possibilidades, esses são os diagramas ternários que melhor caracterizam quimicamente as amostras de solo, minério e sedimentos da bacia de Tijucas do Sul. 

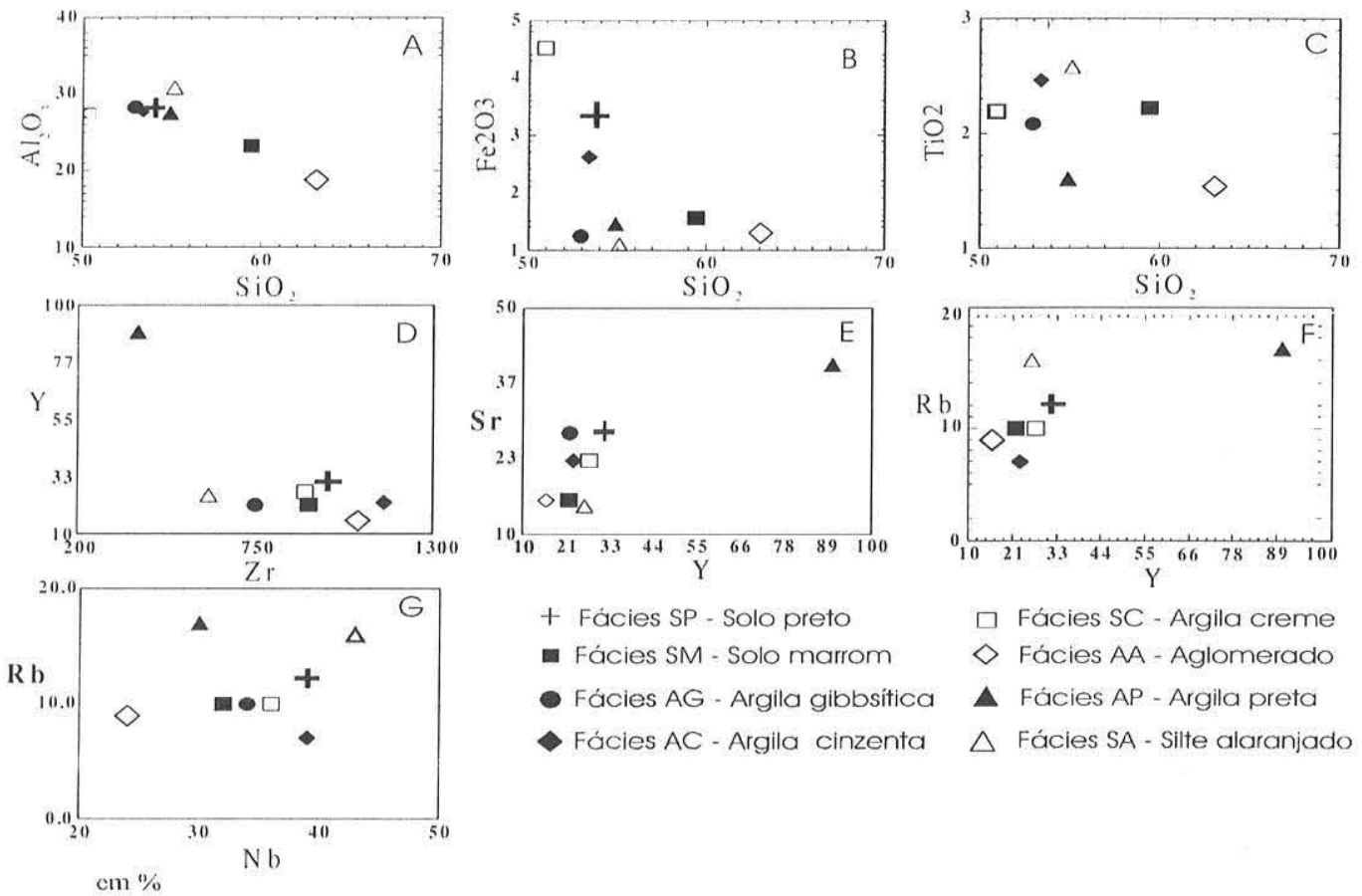

+ Fácies SP - Solo preto

a Fácies SM - Solo marrom

$\square$ Fácies SC - Argila creme

$\diamond$ Fácies AA - Aglomerado

- Fácies AG - Argila gibbsítica

- Fácies AP - Argila preta

- Fácies AC - Argila cinzenta

$\triangle$ Fácies SA - Silte alaranjado

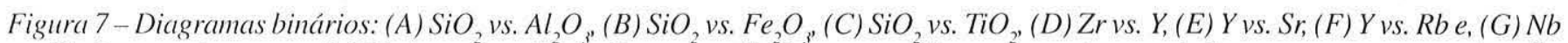
vs. Rb. Entre todas as possibilidades, esses são os diagramas binários que melhor caracterizam quimicamente as amostras de solo, minério e sedimentos da bacia de Tijucas do Sul.

não há lógica na distribuição dos elementos traço nem para os outros óxidos, cujos teores parecem não ter sido influenciados pelos processos de sedimentação, iluviação e eluviação. Como este comportamento da sílica e da alumina pode ser visto na superfície atual (solo SP), aparentemente o processo de modificação dos teores de sílica e alumina está ativo, ocorre em superfície e ocorreu três outras vezes, quando a superfície da pilha sedimentar deve ter ficado exposta ao nível onde hoje estão as amostras TC-4 (=TA-5), TC-9 (=TA-1?) e TC-15 (Fig. 8). Considerado deste modo, a paleo-superfície mais antiga seria $\mathrm{Sn+1}$, depois formaram-se $\mathrm{Sn}+2, \mathrm{Sn}+3$ e a superfície atual, $\mathrm{Sn+4}$ (Fig. 8).

Os comportamentos observados da sílica e da alumina podem ser explicados se for considerado que, na época em que essas superfícies existiram, houve caulinização na zona entre a superfície topográfica e a superfície freática, causada pela lixiviação dos feldspatos sedimentares por águas meteóricas ácidas, conforme descrito por Millot (1964, pag. 377) e por Gomes (1988, pag. 150154), entre outros. Segundo esses autores, o processo se acelera quando o solo for rico em matéria orgânica, que geram ácidos húmicos. Isto explicaria os baixos teores em metais alcalinos das amostras analisadas, já mencionados. As reações que proporcionam a lixiviação da sílica e a concentração (residual) da alumina, neoformando caulinita, seriam:

$$
\begin{aligned}
& 3 \mathrm{KAISi}_{3} \mathrm{O}_{8}+2 \mathrm{H}_{2} \mathrm{O} \rightarrow \mathrm{KAl}_{3} \mathrm{Si}_{3} \mathrm{O}_{10}(\mathrm{OH})_{2}+2 \mathrm{~K}^{+}+2 \mathrm{OH}^{-}+6 \mathrm{SiO}_{2} \\
& \text { feldspato } \mathrm{K} \text { ilita (lixiviado) (lixiviada) } \\
& 4 \mathrm{KAl}_{3} \mathrm{Si}_{3} \mathrm{O}_{10}(\mathrm{OH})_{2}+10 \mathrm{H}_{2} \mathrm{O} \rightarrow 3 \mathrm{Al}_{4} \mathrm{Si}_{4} \mathrm{O}_{10}(\mathrm{OH})_{8}+4 \mathrm{~K}^{+}+4 \mathrm{OH}^{-} \\
& \text {illita caulinita (lixiviado) }
\end{aligned}
$$

Características físico-químicas dos sedimentos e a gênese da gibbsita A Tabela 3 e a figura 9 mostram o $\mathrm{pH}$, a Capacidade de Troca de Cátions (CTC), a quantidade de matéria orgânica (MO) e a quantidade de cátions $\mathrm{H}^{+}, \mathrm{Al}^{3+}, \mathrm{Ca}^{2+}, \mathrm{Mg}^{2+}$ e K $\mathrm{K}^{+}$livres de algumas amostras selecionadas das seções TC, TD e TF (Santos 2000). Estes números informam sobre as reações que ocorrem atualmente nos sedimentos. As análises foram feitas no Laboratório de Solos do Departamento de Agronomia da Universidade Federal do Paraná. $\mathrm{O}$ pH foi medido após diluir as amostras em uma solução de $\mathrm{CaCl}_{2}$ N/200. O CTC foi medido pelo método de saturação da amostra em $\mathrm{NH}^{4+}$ por tratamento em solução saturada em acetato de amônio. Após lavagem e filtragem, o resíduo foi titulado com $\mathrm{HCl}$ e bromocresol verde e os cátions livres $\mathrm{H}^{+}, \mathrm{Al}^{3+}, \mathrm{Ca}^{2+}, \mathrm{Mg}^{2+} \mathrm{e}$ $\mathrm{K}^{+}$foram determinados no filtrado, com os métodos analíticos habituais (Bain \& Smith, 1994).

$\mathrm{O}$ pH ácido, entre 3,6 e 4,1, as CTC menores que 20 e os valores baixos de $\mathrm{K}^{+}$, menores que 0,07 , são típicos de ambientes sedimentares onde há caulinização intensa, causada por forte lixiviação feita por águas meteóricas (Millot 1964, pag. 377; Grim 1968; Gomes 1988, pag. 150-154; Bain \& Smith 1994; entre outros). Este processo é acelerado em ambientes ricos em matéria orgânica, muito mais reativos, como é o caso dos solos SP e SM e da argila lacustre preta AP (Tabela 3 e Fig. 9). Além de teores elevados em $\mathrm{MO}$, essas fácies têm as maiores CTC, o que indica que sua caulinita tem dimensões menores que as com baixa CTC e maior capacidade de suspensão (Velde 1992, p.34).

Os pH menores que 4 e os valores elevados de $\mathrm{H}^{+}+\mathrm{Al}^{3+}$ das fácies SP, SM e AP (Tabela 3 e Fig. 9) estão, também, diretamente relacionados com a elevação da CTC, e são indicativos de um processo de aluminização muito eficiente. Segundo Millot (1964, pag. 377) e Gomes (1988, pag. 153), a aluminização acontece quando a drenagem é excelente, fazendo que a água escoe entre os poros dos sedimentos sem que haja formação de lençol freático. Nesse caso ocorre a dessilicificação dos feldspatos e da caulinita e a 
concentração residual da alumina, formando gibbsita segundo as reações:

$$
\begin{aligned}
& \mathrm{H}^{+}+2 \mathrm{KAlSi}_{3} \mathrm{O}_{8}+9 \mathrm{H}_{2} \mathrm{O} \rightarrow 2 \mathrm{Al}(\mathrm{OH})_{3}+2 \mathrm{~K}^{+}+3 \mathrm{H}_{4} \mathrm{SiO}_{4} \\
& \text { Feldspato } \mathrm{K}_{8} \text { Gibbsita (lixiviado) (lixiviado) } \\
& \mathrm{H}^{+}+3 \mathrm{Al}_{4} \mathrm{Si}_{4} \mathrm{O}_{10}(\mathrm{OH})_{8}+9 \mathrm{H}_{2} \mathrm{O} \rightarrow 12 \mathrm{Al}(\mathrm{OH})_{3}+12 \mathrm{H}_{4} \mathrm{SiO}_{4} \\
& \text { Caulinita } \\
& \text { Gibbsita (lixiviado) }
\end{aligned}
$$
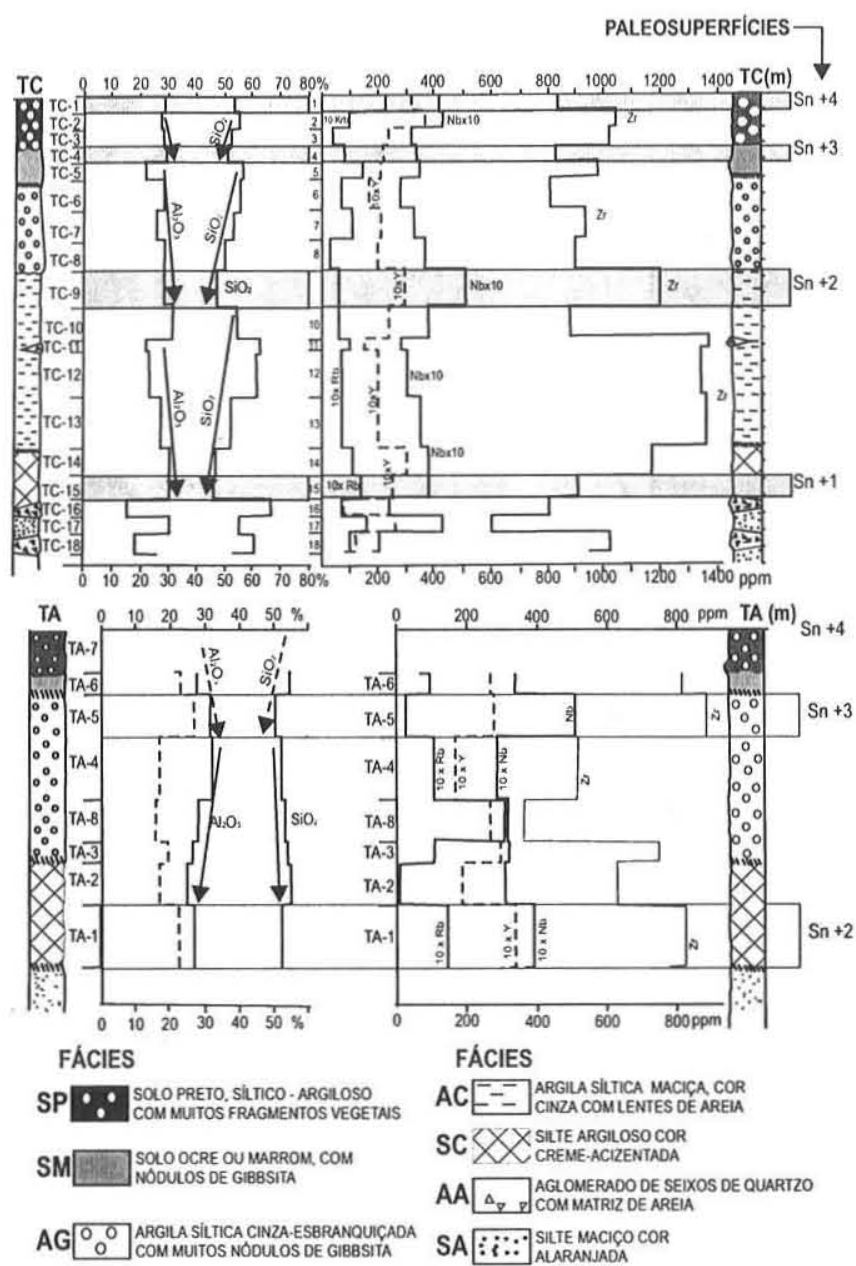

Figura 8-Variação dos teores de $\mathrm{SiO}_{2}, \mathrm{Al}_{2} \mathrm{O}_{3}, \mathrm{TiO}_{2}, \mathrm{Rb}, \mathrm{Y}, \mathrm{Nb}$ e $\mathrm{Zr}$ ao longo das seções TC e TA.
Provavelmente esse seja o processo de formação da gibbsita que ocorre em todas as fácies (Tabela 4), principalmente nas SP, SM e AG, onde forma nódulos (Figs. 3 e 4C e D).

Mineralogia DIFRAÇÃODERAIOSX Em 30 amostras foram feitos difratogramas de esfregaços da fração menor que $0,04 \mathrm{~mm}$, e da fração argila precipitada: (a) sobre lâminas delgadas, sem tratamento, (b) tratadas com glicol-etileno e, (c) queimadas a $550^{\circ} \mathrm{C}$ durante duas horas. Os resultados constam da Tabela 4.

Os difratogramas (Tabela 4) mostram que: (a) A paragênese da maior parte das amostras é composta por quartzo, caulinita, vermiculita, gibbsita, anatásio, ilmenita e magnetita. A presença da vermiculita, uma argila típica de ambientes superficiais, em amostras coletadas a cerca de 10 metros da superfície, indica que toda a pilha sedimentar está sendo recristalizada pela ação de águas superficiais. A gibbsita ocorre em pequenas quantidades em todas as fácies. No campo foi observado que ela forma nódulos nas fácies mais próximas da superfície, muito dessilicificadas. Os óxidos de ferro e de titânio foram trazidos dos diques de basalto existentes em volta da bacia de Tijucas. (b) O feldspato potássico está presente, em pequena quantidade, somente nas fácies desprovidas de nódulos de gibbsita (AC, SC e AA), onde ainda não foi totalmente consumido pela caulinização e gibbsitização. (c) A ilita foi detectada somente nos difratogramas das amostras TA-8 e TD-3, confirmando a quase ausência de potássio, causada pela intensa lixiviação dos sedimentos. (d) O Índice de Hinckley (Ich)é o que melhor reflete a "ordem estrutural global" ou "grau de ordenamento dos folhetos" das caulinitas (Gomes, 1988, p.188190). Calculados a partir dos difratogramas de amostras das seções TA e TC, foram determinados valores entre 0,24 e 0,56 , com média de 0,39 e s $=0,10$ (Tabela 4 e Fig. 10). Esses valores indicam que a caulinita têm cristalinidade baixa a muito baixa. Os mesmos difratogramas mostram o predomínio de cristais com "desordem no eixo b". Estas características estruturais da caulinita de Tijucas do Sul podem estar relacionadas ao baixo grau de diagênese dos sedimentos e à dessilicificação das caulinitas.

A composição mineral "racional" (Gomes, 1988, p.208-210), calculada a partir das análises químicas das amostras (Tabelas 2 e 4), confirma a presença das paragêneses reveladas pelos difratogramas. As composições mineralógicas médias (Tabela 4) são de sedimentos com 45 a $75 \%$ de caulinita, 2 a $41 \%$ de quartzo, 1 a $8 \%$ de gibbsita e 1 a $10 \%$ de óxidos de titânio (ilmenita +

\begin{tabular}{|c|c|c|c|c|c|c|c|c|c|}
\hline AMOSTRA & $\begin{array}{l}\text { FÁCIES } \\
\text { /CÔR }\end{array}$ & $\begin{array}{c}\mathrm{pH} \\
\left(\mathrm{CaCl}_{2}\right)\end{array}$ & $\begin{array}{c}\mathrm{Al}^{3+} \\
\mathrm{meq} / 100 \mathrm{~g}\end{array}$ & $\begin{array}{c}\mathrm{A} \\
\mathrm{H}^{+}+\mathrm{Al}^{3+} \\
\text { meq } / 100 \mathrm{~g}\end{array}$ & $\begin{array}{c}\mathrm{B} \\
\mathrm{Ca}^{2+} \\
\mathrm{meq} / 100 \mathrm{~g}\end{array}$ & $\begin{array}{c}\mathrm{C} \\
\mathrm{Mg}^{2+} \\
\mathrm{meg} / 100 \mathrm{~g}\end{array}$ & $\begin{array}{c}\mathrm{D} \\
\mathrm{K}^{+} \\
\mathrm{meq} / \mathrm{lo0g}\end{array}$ & $\begin{array}{c}\text { CTC } \\
(A+B+C+D) \\
\text { meq } / 100 \mathrm{~g}\end{array}$ & $\begin{array}{l}\mathrm{MO} \\
(\%)\end{array}$ \\
\hline TC-01 & SP/preta & 4,0 & 5,0 & 20.6 & 1,4 & 0.6 & 0,02 & 22.6 & 55.9 \\
\hline TC -03 & SP/preta & 4.1 & 1,8 & 11,3 & 0.8 & 0.4 & 0,02 & 12.5 & 5.6 \\
\hline TC-04 & $\mathrm{SM} / \mathrm{marron}$ & 3.9 & 2,9 & 12.1 & 0.7 & 0.4 & 0.03 & 13.2 & 4,3 \\
\hline TC -06 & $\mathrm{AG} / \mathrm{cinza}$ & 3.9 & 2,0 & 8,4 & 0,6 & 0.4 & 0.03 & 9.4 & 3,8 \\
\hline TC- 12 & $\mathrm{AC} / \mathrm{cinza}$ & 3,9 & 2,0 & 7,2 & 0,8 & 0,4 & 0,01 & 8,4 & 3,0 \\
\hline TF-()I & $\mathrm{SM} / \mathrm{marron}$ & 3,6 & 4,6 & 16,3 & 1,0 & 0,4 & 0,04 & 17.7 & 21,0 \\
\hline TD $-(0) 3$ & AP/preta & 3,6 & 4,3 & 16,3 & 1,7 & 0,5 & 0.07 & 18,3 & 24,0 \\
\hline
\end{tabular}
anatásio + "outros óxido").

Tabela 3 - Características físico-químicas de solos, minérios e sedimentos da Mina fazendinha. $\mathrm{pH} /\left(\mathrm{CaCl}_{2}\right)=\mathrm{pH}$ da amostra medido em solução de $\mathrm{CaCl}, \mathrm{N} / 200 . C T C=$ Capacidade de Troca de Cátions. $\mathrm{MO}=$ Matéria orgânica. meq $/ 100 \mathrm{~g}=$ miliequivalentes em 100 gramas. Os símbolos das fácies são os mesmos da figura 3. 


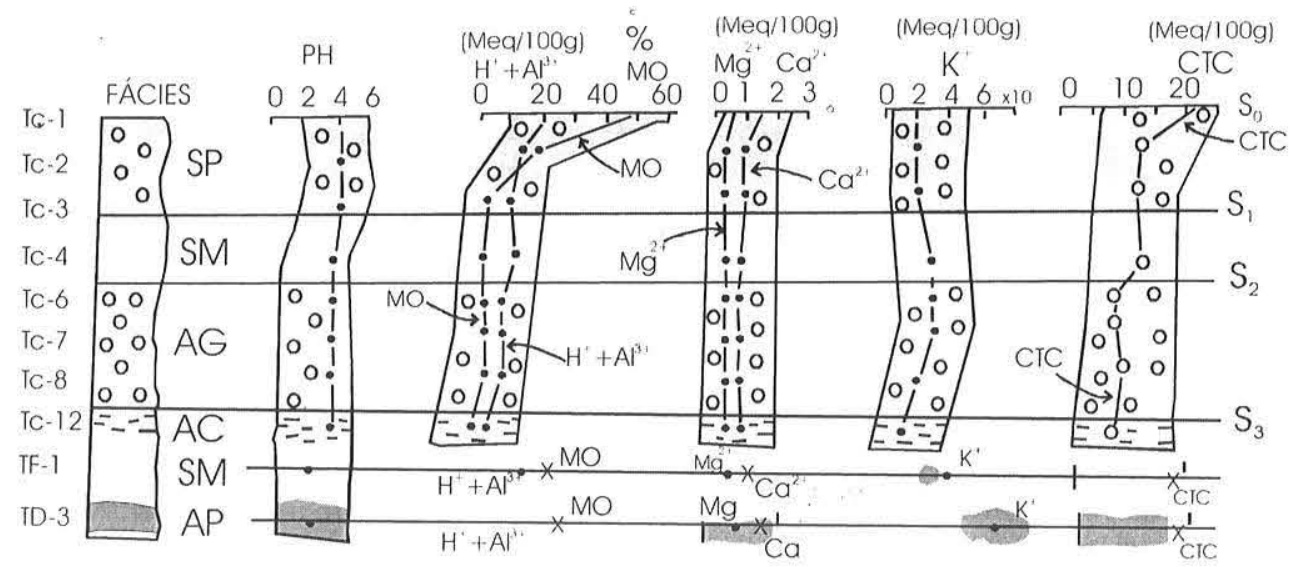

Figura 9 - Variação do $\mathrm{pH}$, do CTC e dos teores em $\mathrm{H}^{+}, \mathrm{Al}^{3+}, \mathrm{Ca}^{2+}, \mathrm{Mg}^{2+}$ e $\mathrm{K}^{+}$na parte superior da seção TC e em amostras selecionadas das seções TF e TD. Os símbolos e abreviações são os mesmos usados na tabela 4.

Tabela 4 - Composição mineralógica média da fração < 0,04 mm (325 mesh) das fácies de solo, minério e sedimentos da mina Fazendinha, calculada a partir das composições químicas das amostras ( $s=$ desvio padrão; "Óxido Ti" = mineral com Ti oxidado; Óxido $\mathrm{Fe}=$ mineral com $\mathrm{Fe}$ oxidado).

\begin{tabular}{|c|c|c|c|c|c|c|c|c|c|}
\hline \multicolumn{8}{|c|}{ Composição mineralógica média calculada, em \% (s = desvio padrão) } & \multirow[b]{2}{*}{$\begin{array}{c}\text { Mineralogia } \\
\text { analisada }\end{array}$} & \multirow{2}{*}{$\begin{array}{l}\text { Indice de } \\
\text { Hinckley } \\
\text { (lch) }\end{array}$} \\
\hline $\begin{array}{l}\text { cies (110 de } \\
\text { mostras) }\end{array}$ & Caulinita & Quartzo & Gibbsita & Ilita & Ilmenita & "Óxido Ti" & "Óxido Fe" & & \\
\hline SP' (3) & 69.8 & 20.2 & nd & 1.5 & 10,3 & $<0,1$ & 1,5 & Qzo, caul, verm, gibb, ana, ilm, & $0,24 a$ \\
\hline s & 1.7 & 1,9 & nd & 0,4 & 1,3 & nd & 0,2 & $\mathrm{mgt}$ & 0.31 \\
\hline s & 16,8 & 18,6 & 2,3 & 0.5 & 1,4 & 0,4 & nd & & \\
\hline$A G(9)$ & 68,6 & 19,7 & 6,2 & 1,9 & 2,6 & 1,1 & 0,1 & Qzo, caul, ilita,verm, gibb, ana, & $0.30 \mathrm{a}$ \\
\hline $\mathrm{s}$ & 7,1 & 5,3 & 3,0 & 1,9 & 1,3 & 0,6 & nd & $\mathrm{ilm}, \mathrm{mgt}$ & 0.56 \\
\hline $\mathrm{SC}(5)$ & 66,5 & 18,1 & 9,2 & 1,7 & 4,2 & 0,5 & $<0,1$ & Qzo, caul, verm, gibb, fk, ana, & 0,29 a \\
\hline $\mathrm{s}$ & 7,6 & 6,9 & 1,0 & 0,4 & 2,3 & 0,2 & nd & ilm, mgt & 0,43 \\
\hline$\overline{A A}(3)$ & 45.4 & 40.9 & 8.6 & 1.5 & 3.5 & 0.4 & 1,0 & Qzo, caul, verm, gibb, fk (ana, & $0.46 a$ \\
\hline$s$ & 9.5 & 6.3 & 6.0 & 0.9 & 2.2 & 0.1 & nd & ilm, mg) & 0.56 \\
\hline AP $(8)$ & 6.5 .5 & 22.5 & 5.9 & 2.8 & 3.0 & 0,6 & $<0,1$ & Qzo, caul, verm, gibb & \\
\hline$s$ & 6.2 & 5,0 & 2,2 & 1.6 & 1,8 & 0.3 & nd & & \\
\hline SA (1) & 75.7 & 18.9 & $<0,1$ & 1.7 & 2,2 & 1.5 & $<0,1$ & Qzo, caul, verm, gibb & 0,47 \\
\hline
\end{tabular}

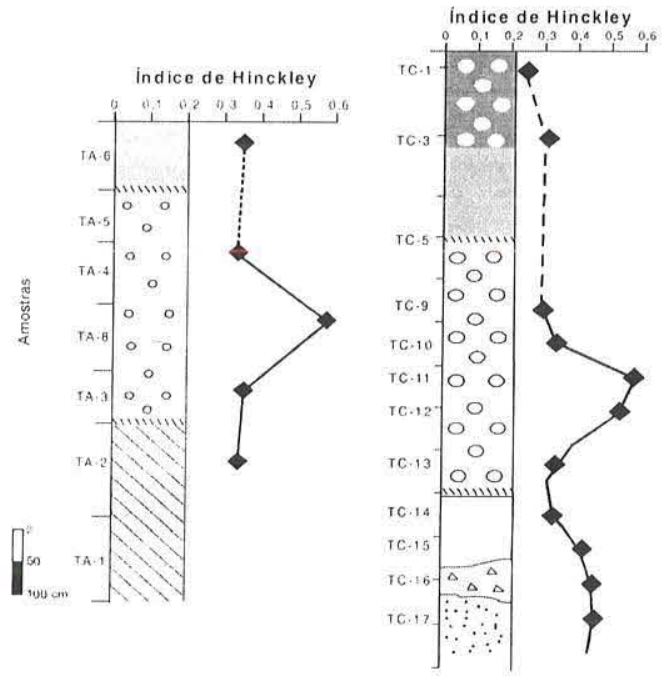

Figura 10 - Variação do indice de Hinckley determinado em amostras coletadas nas seções TA e TC.
MICROSCOPIA DE VARREDURA (MEV) EANÁLISE QUÍMICA PONTUAL(EDS) Santos (2000) analisou as frações argila das amostras TA-1, 2, 3, 4, 6 e 8 com um microscópio eletrônico de varredura com capacidade para fazer micro-análise pontual por energia dispersiva (MEV-EDS). As análises foram feitas com um equipamento Philips do LAC-COPEL - Laboratório Central da Companhia de Eletricidade do Paraná. Essas análises revelaram que: (a) Não há haloisita nos sedimentos de Tijucas do Sul. (b) Há predomínio de caulinita detrítica, identificada por sua forma de placa anédrica, com bordas irregulares e dimensão menor que 0,5

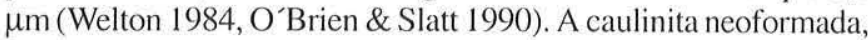
com estrutura "em acordeon" (Shole 1979), é menos freqüente. (c) Foram identificados cristais losangulares, euédricos, com dimensões menores que $0,2 \mu \mathrm{m}$. A análise pontual desses cristais mostrou serem minerais de titânio. A forma e a composição sugerem que sejam cristais de anatásio. (d) Análises pontuais de cristais de caulinita revelaram a presença de titânio e ferro. È provável que esses cátions tenham sido incorporados devido aos graus elevados de desordem estrutural dos argilominerais, conforme indicado pelos baixos Ich. O Ti e o Fe dos argilominerais aparecem nas 
composições mineralógicas "racionais" como "ilmenita" e "óxidos de Ti e Fe" (Tabela 4).

CONCLUSÕES A bacia sedimentar de Tijucas do Sul contém o maior depósito de argila caulinítica da região sul do país. Está preenchida por sedimentos com baixo grau de diagênese, predominando argilas e siltes argilosos sedimentados em ambiente fluviais, de planície de inundação, e lacustres, em menor proporção. A pilha sedimentar está sendo intensamente lixiviada por águas superficiais, o que causa dessilicificação dos feldspatos, gerando caulinita e gibbsita, e da caulinita, gerando gibbsita. Nos sedimentos mais próximos da superfície o processo de aluminização avançou a ponto de formar grande quantidade de nódulos de gibbsita + caulinita. Há indicações de que esse processo tenha ocorrido em ao menos três outros períodos, nos quais a paleo-superfície da pilha sedimentar ficou exposta à ação de águas meteóricas por longo tempo, proporcionando dessilicificação e caulinização de camadas atualmente soterradas e distantes da superfície.

A composições químicas das fácies de sedimentos presentes na bacia é pouco variada. Destaca-se unicamente a fácies AP, argila preta, unica fácies lacustre, devido aos teores elevados de matéria orgânica, à cor preta, aos teores elevados de $\mathrm{Y}$ e por suas propriedades cerâmicas, semelhantes às das "ball clays". As argi- las têm teores elevados em Ti e Fe, que estão incorporados nos argilominerais ou ocorrem como micro-fragmentos de minerais, trazidos dos diques de basalto existentes em grande quantidade em torno da bacia de Tijucas do Sul.

A fração dos sedimentos menor que $0,04 \mathrm{~mm}$ tem 45 a $75 \%$ de caulinita, 2 a $41 \%$ de quartzo, 1 a $8 \%$ de gibbsita e 1 a $10 \%$ de óxidos de titânio (ilmenita + anatásio + "outros óxido"). A análise difratométrica permitiu determinar que a cristalinidade das caulinitas é baixa a muito baixa, e que predominam cristais com "desordem no eixo b". Estas características estruturais podem estar relacionadas ao baixo grau de diagênese dos sedimentos e à dessilicificação das caulinitas.

Análises MEV-EDS mostraram que não há haloisita e que predominam caulinitas detríticas, menores que $0,5 \mu \mathrm{m}$. Caulinitas neoformadas, com estruturas "em acordeon", são menos freqüentes. Foram identificados cristais cujas formas e composições sugerem que sejam cristais de anatásio, provavelmente trazidos dos diques de basalto que ocorrem em volta da Bacia de Tijucas do Sul. Titânio e ferro ocorrem incorporados nas caulinitas, provavelmente devido aos seus elevados graus de desordem estrutural.

Agradecimentos Aos revisores da RBG pelas sugestões ao manuscrito.

\section{Referências}

Ab’Saber A.N. \& Bigarella J.J. 1961. Superfícies aplainadas do Primeiro Planalto do Paraná. Bol. Par: Geogrecifia, 4 e 5:116-125.

Aumond J.J. 1993. Aspectos geológicos de algumas argilas para cerâmica branca da Bacia de Tijucas do Sul. Cerâmica, 39(260):24-26.

Bain D.C. \& Smith B.F.L. 1994. Chemical analysis. In M.J. Wilson (ed.) Clay Mineralogy: Spectroscopic and Chemical Determinative Methods. London, Chapman \& Hall, 300-327.

Bigarella J.J. \& Salamuni R. 1959. Notas complementares à planta geológica da cidade de Curitiba e arredores. Bol. Inst. Pesq. Tec., 40:1-14.

Bigarella J.J.. Salamuni R., Ab’Saber A.N. 1961. Origem e ambiente de deposição da bacia de Curitiba. Bol. Par: Geografia, 4 e 5:71-81.

Bigarella J.J. \& Salamuni R. 1962. Caracteres texturais dos sedimentos da bacia de Curitiba. Bol. Geoc. Univ. Fed. Paraná. 7:1-164.

DNPM-MINEROPAR 1989. Mapa Geológico do Estado do Paraná 1:650.000.

Gomes C.F. 1988. Argilas - O que são e para que servem. Lisboa, Fund. Calouste Gulbenkian, $457 \mathrm{p}$.

Grim R.E. 1968. Clay Mineralogy. New York, MacGraw Hill, 596 p.

O’Brien N.R. \& Slatt R.M. 1991. Argillaceous Rock Atlas. New York,
Springer-Verlag, $141 \mathrm{p}$.

Millot G. 1964. Géologie des Argiles. Paris, Masson et Cie, Éditeurs, $499 \mathrm{p}$.

Santos E.R. 2000. Caracterização Mineralógica e Contexto Geológico das Argilas da Mina Fazendinha, Tijucas do Sul - PR.. Dissertação de Mestrado, Departamento de Geologia, Universidade Federal do Paraná, Curitiba, 140 p.

Shole P.A. 1979. A collour illustred guide to constituents, textures, cements and porosities of sandstones and associated rocks. AAPG Memoir $28,201 \mathrm{p}$.

Trein E., Fuck R.A., Muratori A. 1969. Geologia da folha de Tijucas do Sul. Comissão da Carta Geológica do Paraná. Relatório Anexo, 68p.

Velde B. 1992. Introduction to Clay Minerals. London, Chapman \& Hall, $198 \mathrm{p}$.

Welton J.E. 1984. SEM Petrology Atlas - Methods in Exploration Series. Tulsa, AAPG, 237 p.

Manuscrito A-1418

Recebido em 10 de março de 2003

Revisão dos autores em 10 de abril de 2004 Revisão aceita em 15 de abril de 2004 